\title{
New Development in Leaching of Ilmenite Ore and Titania Slag Mixture Using Sulfate Process
}

\author{
Taysser A. Lasheen ${ }^{1}$, Ebtsam A. Saad ${ }^{2}$, Mohamed E. H. Shalabi ${ }^{3}$ and Waleed M. Abo-Elhamd ${ }^{1 *}$ \\ ${ }^{I}$ Nuclear Materials Authority, P.O. Box 530 El Maadi, Cairo, Egypt, \\ ${ }^{2}$ Department of Chemistry, Faculty of Science, Ain Shams University, Egypt, \\ ${ }^{3}$ Central Metallurgical Research and Development Institute
}

ARTICLE INFO

Article history:

Received 07 September 2015

Accepted 13 October 2015

Keywords:

Ilmenite ore;

Titania slag;

Sulfuric acid.

\section{Introduction}

Titanium dioxide is an important intermediate gradient in the manufacture of paints, pigments, welding rode coating, ceramics, papers, painting inks,.... etc. and other related industries which is widely used in cosmetics and food products because of its high index of refraction and non-toxic nature ${ }^{[1]}$ and ${ }^{[2]}$. It is also used because of its photocatalytic activity ${ }^{[3]}$. The main titanium bearing of technical importance are rutile and ilmenite. As the reserves of rutile are rather limited, special attention has been paid to ilmenite deposits whish occur extensively in various parts of the world. The titanium dioxide industry accounts for nearly $95 \%$ by weight of the world consumption of titanium bearing minerals, whilst the balance is used in making titanium metal, non titanium base alloys, carbides, fiber glass and chemicals.

In Egypt, abundance reserves of naturally accruing ilmenite ores are available and located at two main deposits. The first deposits estimated to be about 50 million tons are present at Abu Ghalaga mines of ELNasr phosphate company eastern desert. The second ilmenite ore occurs as an essential constituent of beach places, called black sands, whish accumulate and become enriched along the shores of the Nile delta, particularly at Rosetta and Damietta.

White titanium dioxide pigment has been produced by two main processes; namely the sulfate and the chloride processes. Each of these two routes requires a different feedstock. In the sulfate process, the feedstock includes a finely ground ilmenite concentrate of minimum $44 \%$ $\mathrm{TiO}_{2}$ or a sulfatable titanium slag of $78 \% \mathrm{TiO}_{2}$.

\footnotetext{
* Corresponding author.

E-mail address: Waleed_chemistry96@yahoo.com
}

Pyrometallurgical production of these feedstocks includes mainly ilmenite smelting and roasting. Smelting produces a high titanium slag and a low manganese iron by-product and this is mainly conducted in South Africa, Canada and Norway. On the other hand, ilmenite roasting to synthetic rutile $\left(91-95 \% \mathrm{TiO}_{2}\right)$ involves two main variants; namely, the Becher Process (used in Australia) in which an ilmenite grade of $57-63 \% \mathrm{TiO}_{2}$ is reduced with coal and metallic iron is rusted away ${ }^{[4]}$ and the Benelite Process ${ }^{[5]}$ used in USA, India and Malaysia in which an acid leaching step follows the roasting process. Both can treat a wide range of ilmenite (50-63\% $\mathrm{TiO}_{2}$ ).

In the chloride process, rutile $\left(\mathrm{TiO}_{2}\right)$ is utilized as a raw material. However, shortage of natural rutile has encouraged research efforts to convert ilmenite into high titanium slag or synthetic rutile.

To realize this objective, several processes have been developed that depend upon pyrometallurgical and/or hydrometallurgical treatment of ilmenite deposits to eliminate most of the iron content and other possible impurities ${ }^{[6-11]}$. These processes include the partial reduction of iron at high temperature to $\mathrm{Fe}(\mathrm{II})$ state which is more amenable to acid leaching or its peroxidation followed by partial reduction to $\mathrm{Fe}(\mathrm{II})$ or else to metallic iron. Alternatively, ilmenite ore can be smelted in the presence of a carbonaceous reducing agent in an electric furnace where two saleable products are obtained; namely high quality pig iron and a titania rich slag containing typically $80-85 \% \mathrm{TiO}_{2},{ }^{[12]}$. In such a treatment, the composition of the titania slag product is chemically and mineralogical different from ilmenite. 
According to ${ }^{[10]}$ titanium is present in ilmenite as Ti(IV) and about $20 \%$ of iron is present as $\mathrm{Fe}(\mathrm{IIII})$ and the rest as $\mathrm{Fe}(\mathrm{II})$. However, titanium in the titania slag occurs as $\mathrm{Ti}(\mathrm{III})$ and $\mathrm{Ti}(\mathrm{IV})$ and most of the associated iron is present as $\mathrm{Fe}(\mathrm{II})$. While Ti and $\mathrm{Fe}$ atoms in ilmenite are arranged in the form of hexagonal crystals.

Due to these differences and the complex nature of titania slag, the above processes developed for beneficiating ilmenite concentrates are not applicable in some cases for titania slag. Other processes have thus been developed for its beneficiation including chlorination or fluxing of the associated impurities, sulfatisation and oxidation-reduction roasting or else salt roasting. The first process of chlorination has been suggested by ${ }^{[13-16]}$ for treating of titania slag containing at least an alkaline earth impurity. In this procedure, the slag is treated with $\mathrm{HCl}$ gas at high temperature in the absence of oxygen to prevent oxidation of Ti(III). Iron and alkaline earth chlorides are formed and subsequently water or $\mathrm{HCl}$ acid leached. Alternatively, ${ }^{[17]}$ have proposed upgrading the slag through heating in presence of a glass forming fluxing agent, such as $\mathrm{P}_{2} \mathrm{O}_{5}$ or the oxides of $\mathrm{Na}, \mathrm{K}$ or $\mathrm{Si}$, which results in the formation of a crystalline rutile phase and a glassy phase containing most of the impurities which would be removed by treatment with a mineral acid. In titania slag sulfatisation, ${ }^{[18]}$ propose mixing of the slag with an alkaline salt e.g $\mathrm{Na}_{2} \mathrm{CO}_{3}$ before reaction with either $\mathrm{SO}_{3}$ or with mixtures of $\mathrm{SO}_{2}$ and $\mathrm{O}_{2}$ at $700^{\circ} \mathrm{C}$ to $1100^{\circ} \mathrm{C}$ Alternatively, sulfidisation in presence of a mixture of $\mathrm{H}_{2} \mathrm{~S}+\mathrm{N}_{2}$ and $\mathrm{S}_{2}+\mathrm{C}$ at $1100^{\circ} \mathrm{C}$ was proposed by ${ }^{[19]}$, followed by water or $\mathrm{HCl}$ acid leaching of the iron sulfides at room temperature.

Both Van Dyk, et al. ${ }^{[10]}$ and Borowiec, et al. ${ }^{[20]}$ have indicated that slag can be directly upgraded by oxidation reduction thermal treatment before acid leaching. Borowiec, et al. ${ }^{[20]}$ described a process that is now commercially employed for upgrading Sorel slag (78.3$84.84 \mathrm{TiO}_{2} \%$ ). It involves thermal treatment where oxidation is accomplished at temperature $\left(1000^{\circ} \mathrm{C}\right.$ $1050^{\circ} \mathrm{C}$ ) for $1-1.5 \mathrm{~h}$, and the succeeding reduction step is performed at $800^{\circ} \mathrm{C}$ for $1 \mathrm{~h}$ using smelter gas. In the oxidation step, $\mathrm{Fe}$ (II) and $\mathrm{Ti}$ (III) are converted to $\mathrm{Fe}(\mathrm{III})$ and $\mathrm{Ti}(\mathrm{IV})$ which help in decomposing the glassy phase. In the subsequent reduction step Fe(III) is reduced back to $\mathrm{Fe}$ (II) and a $\mathrm{MgO}$ rich ilmenite-geikielite solid solution is formed which is more amenable to leaching than the original phases. However, proper pre-treatment of the slag is required involving fine sizing of the titania to allow iron reactions at the exposed surfaces during oxidation and reduction. The treated slag is then leached at $145-155^{\circ} \mathrm{C}$ in a two stages procedure using $20 \% \mathrm{HCl}$ for $6 \mathrm{~h}$ or in one stage procedure for $8 \mathrm{~h}$ under pressure. The assay of the beneficiated slag after washing and calcinations attains $95 \% \mathrm{TiO}_{2}$.

In the present work, the target was to realize the dissolution of the Rosetta beach ilmenite concentrate and Titania rich slag as reductant in dilute sulfuric acid to prevent the hardness of the pulp in the reactor and enhance the extraction and determine the optimum conditions at which maximum dissolution of titanium would be obtained. The aim was to dissolve titanium as a pre-requisite for its separation by hydrolysis to obtain titanium dioxide. For this purpose, several series of dissolution experiments were performed in which the slag/ilmenite ratio, acid concentration and solid/liquid ratio were varied. The effects of temperature and reaction time have also been studied.

\section{Materials and Methods}

\section{Characteristics of Rosetta ilmenite concentrate and titania slag}

The sample obtained from Rosetta beach ilmenite concentrate was kindly provided by the Black Sands project of the Nuclear Materials Authority (NMA). The sample was separated from the tabling of bulk Rosetta black sand concentrate as a moderately magnetic fraction using a cross-belt magnetic separator (model Dinges 3EBK). Three fractions were obtained, namely, a highly magnetic fraction (mainly magnetite), a moderately magnetic fraction (mainly ilmenite), and a non-magnetic fraction (garnet, colored silicates, rutile, monazite and zircon mineral grains). Mineralogically, the obtained ilmenite concentrate is moderately contaminated with trace amounts of magnetic zircon, rutile or leucoxene, chromite and chrome-spinel. This sample has been chemically analyzed in the present work for both the major and minor oxides as shown in (Table 1).

Table 1: Chemical compositions of East Rosetta ilmenite concentrate

\begin{tabular}{|c|c|}
\hline Oxides & Wt.\% \\
\hline $\mathrm{TiO}_{2}$ & 43.95 \\
\hline $\mathrm{FeO}$ & 27.90 \\
\hline $\mathrm{Fe}_{2} \mathrm{O}_{3}$ & 22.01 \\
\hline $\mathrm{MnO}$ & 1.17 \\
\hline $\mathrm{V}_{2} \mathrm{O}_{5}$ & 0.175 \\
\hline $\mathrm{Cr}_{2} \mathrm{O}_{3}$ & 0.27 \\
\hline $\mathrm{MgO}$ & 0.70 \\
\hline $\mathrm{Al}_{2} \mathrm{O}_{3}$ & 1.00 \\
\hline $\mathrm{CaO}$ & 0.51 \\
\hline $\mathrm{SiO}_{2}$ & 0.74 \\
\hline $\mathrm{P}_{2} \mathrm{O}_{5}$ & 0.28 \\
\hline
\end{tabular}

A titania slag sample was prepared from Rosetta ilmenite by its carbothermal reduction in an electric arc furnace and was kindly provided from the Nuclear Materials Authority (NMA) titanium project. The obtained titania slag blocks were crushed and sized and a representative sample of about $50 \mathrm{~kg}$ was obtained. A sample ground to -325 mesh was then subjected to chemicals and atomic absorption spectroscopic analysis as shown in (Table 2). 
Table 2: Chemical compositions of the titania slag

\begin{tabular}{|c|c|}
\hline Oxides & Wt.\% \\
\hline $\mathrm{TiO}_{2}$ & 71.94 \\
\hline $\mathrm{Fe}^{\mathrm{t}}$ & 12.59 \\
\hline $\mathrm{MnO}$ & 1.58 \\
\hline $\mathrm{V}_{2} \mathrm{O}_{5}$ & 0.56 \\
\hline $\mathrm{Cr}_{2} \mathrm{O}_{3}$ & 0.41 \\
\hline $\mathrm{MgO}$ & 0.59 \\
\hline $\mathrm{Al}_{2} \mathrm{O}_{3}$ & 1.90 \\
\hline $\mathrm{CaO}$ & 0.79 \\
\hline $\mathrm{SiO}_{2}$ & 8.91 \\
\hline $\mathrm{P}_{2} \mathrm{O}_{5}$ & 0.06 \\
\hline
\end{tabular}

\section{Methods}

The dissolution experiments were performed in $500 \mathrm{ml}$ conical flasks fitted with a reflux condenser. After adding the required amounts of the ilmenite concentrate and slag sample and sulfuric acid solution, the obtained slurry was agitated at various temperatures at $350 \mathrm{rpm}$. At the end of each dissolution experiment, the slurry was filtered, washed with distilled water and the filtrate was analyzed for iron and titanium to calculate their dissolution efficiencies. The ilmenite concentrate and slag were analyzed by firstly fusion with potassium pyro-sulfate. Titanium and total iron analyses of feed, products and filtrates were determined using colorimetric and titrimetric analytical methods respectively. Total iron was titrimetrically determined against EDTA using sulfosalicylic acid while the ferrous content was analyzed titrimetrically against standard potassium dichromate. The spectrophotometric determination of titanium content was performed at 430 $\mathrm{nm}$ using tiron as complexing agent (Unicam UV2-100). Both calcium and magnesium were titrimetrically determined against EDTA using murexide and Eriochrome Black $\mathrm{T}$ indicators. The molybdate reagent in the presence of tartaric acid has been used for determination of the silica content. Analysis of the trace elements present ( $\mathrm{Cr}, \mathrm{V}$ and $\mathrm{Mn}$ ) was performed by means of an atomic absorption (Unicam 969 Model) at $357.9,318.4$ and $279.5 \mathrm{~nm}$, respectively.

\section{Results and discussion}

\section{Effect of slag/ilmenite ratio}

To study the effect of slag/ilmenite ratio several dissolution experiments were performed using slag percent varying from $10 \%$ to $100 \%$. The other dissolution parameters were fixed at acid concentration $10 \mathrm{M} ; \mathrm{S} / \mathrm{L}$ ratio $=1 / 4$; temperature $140^{\circ} \mathrm{C} ; 3 \mathrm{~h}$ reaction time and ilmenite grain size- 325 mesh. The obtained results are plotted in Fig. 1. The results indicate that the dissolution of titanium is dependent on the increase in the slag percent up to $20 \%$ which suitable to make reduction for ilmenite and the excess of slag percent will decrease titanium dissolution due to the large amount of slag that needs hard conditions as high concentrated acid and high temperature.

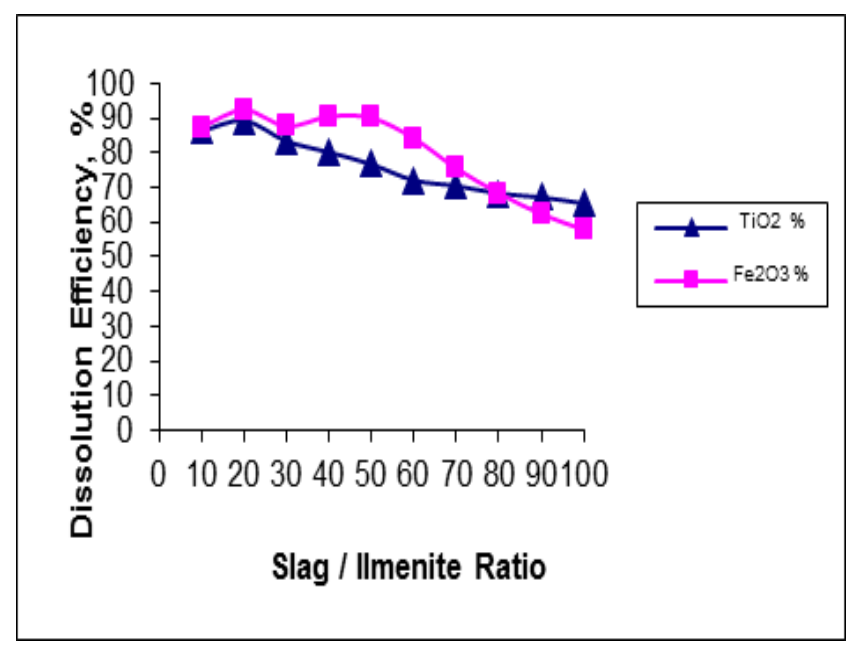

Fig 1: Effect of slag/ilmenite ratio on titanium and iron dissolution from ilmenite and slag mixing $\left(10 \mathrm{M} \mathrm{H}_{2} \mathrm{SO}_{4}, 3\right.$ h, S/L $\left.1 / 4,140^{\circ} \mathrm{C}\right)$.

\section{Effect of acid concentration}

In the present work, several dissolution experiments were performed using sulfuric acid concentrations varying from $1.84 \mathrm{M}$ to $11.03 \mathrm{M}$. The other dissolution parameters were fixed at slag $20 \%$; S/L ratio $=1 / 4$; temperature $140^{\circ} \mathrm{C} ; 3 \mathrm{~h}$ reaction time and ilmenite grain size-325 mesh. The obtained results are plotted in Fig. 2. From the obtained results, it is clearly evident that the dissolution efficiency of $\mathrm{TiO}_{2}$ and total iron is strongly dependent on the acid concentration. In $9.2 \mathrm{M} \mathrm{H}_{2} \mathrm{SO}_{4}$ about $89 \%$ of titanium and $92 \%$ of iron are dissolved. It is found that increasing the sulfuric acid concentration leads to decreasing the recovery extent of $\mathrm{TiO}_{2}$ and total Fe; this may be explained by the fact that high concentration of sulfuric acid enhances its oxidizing effect which forms a passive layer of $\mathrm{Fe}_{3} \mathrm{O}_{4}$ which prevents deeper acid attack. This oxidizing effect is more pronounced due to the smaller particle size.

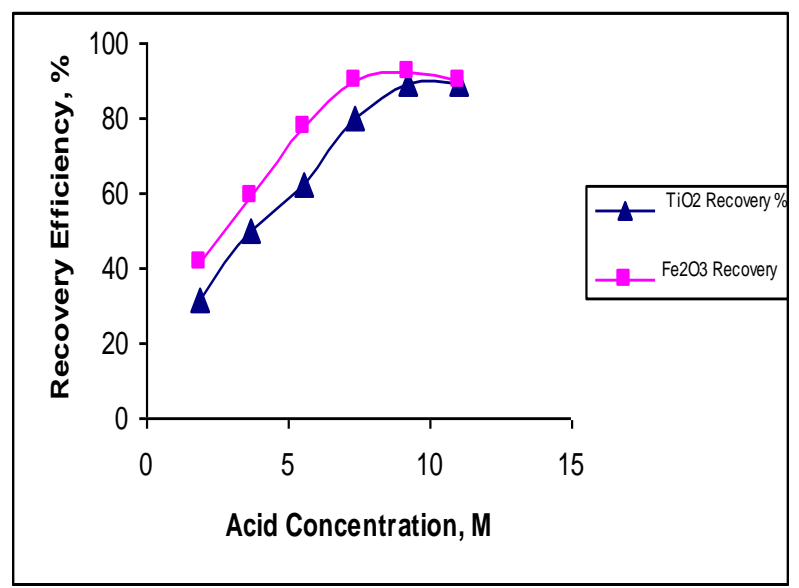

Fig 2: Effect of acid concentration on titanium and iron dissolution from ilmenite and slag mixing (slag $20 \%, 140^{\circ} \mathrm{C}$, $3 \mathrm{~h}, \mathrm{~S} / \mathrm{L}$ ratio $1 / 4)$. 


\section{Effect of liquid/Solid ratio}

Working with $9.2 \mathrm{M} \mathrm{H}_{2} \mathrm{SO}_{4}$, the effect of pulp density was studied in the range of solid to liquid ratio of $1 / 1$ to 1/6. The obtained results are plotted in Fig. 3. In the curve the recovery percent of $\mathrm{TiO}_{2}$ and total iron $\mathrm{Fe}$ increase with increasing the amount of sulfuric acid until reach 1:5 sample / acid ratio. Any further increase of sulfuric acid has no significant effect on increasing $\mathrm{TiO}_{2}$ and total Fe recovery extents.

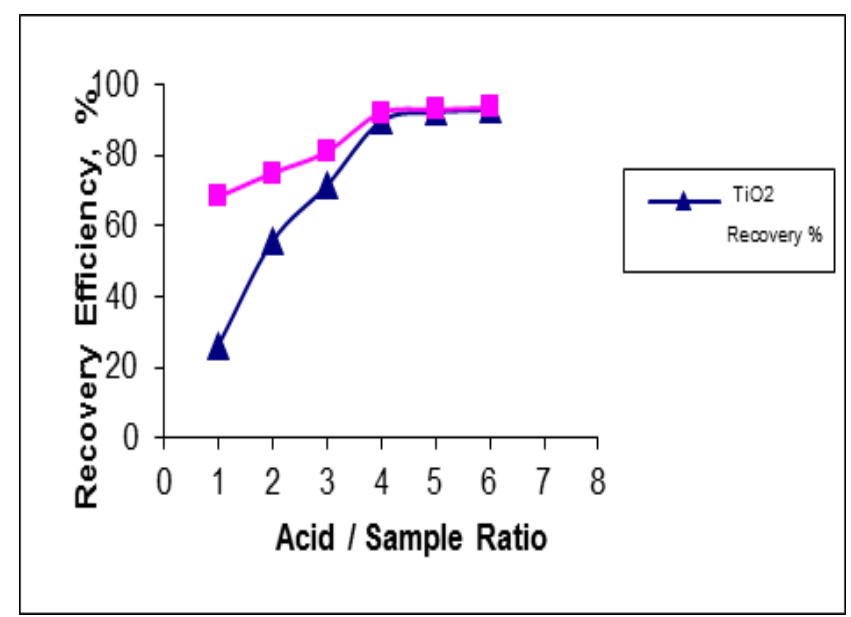

Fig 3: Effect of pulp density on the dissolution of titanium and iron dissolution from ilmenite and slag mixing (slag $20 \%, 140^{\circ} \mathrm{C}, 3 \mathrm{~h}, 9.2 \mathrm{M} \mathrm{H}_{2} \mathrm{SO}_{4}$ ).

\section{Effect of time}

To study the effect of time upon ilmenite and slag dissolution, four experiments were performed at different time periods ranging from 1 to $5 \mathrm{~h}$ using -325 mesh size ore. The results in Fig. 4 show that at 1 to $4 \mathrm{~h}$, the dissolution efficiency of titanium increased from about 42.1 to about $94 \%$ while that of iron has increased from about 48.6 to about $98.9 \%$. Extending the leaching time from 4 to $5 \mathrm{~h}$ however, has a slight adverse effect upon the dissolution of titanium and total iron due to hydrolysis effects. Therefore, $4 \mathrm{~h}$ would represent an optimum time for maximizing the leaching of both titanium and total iron.

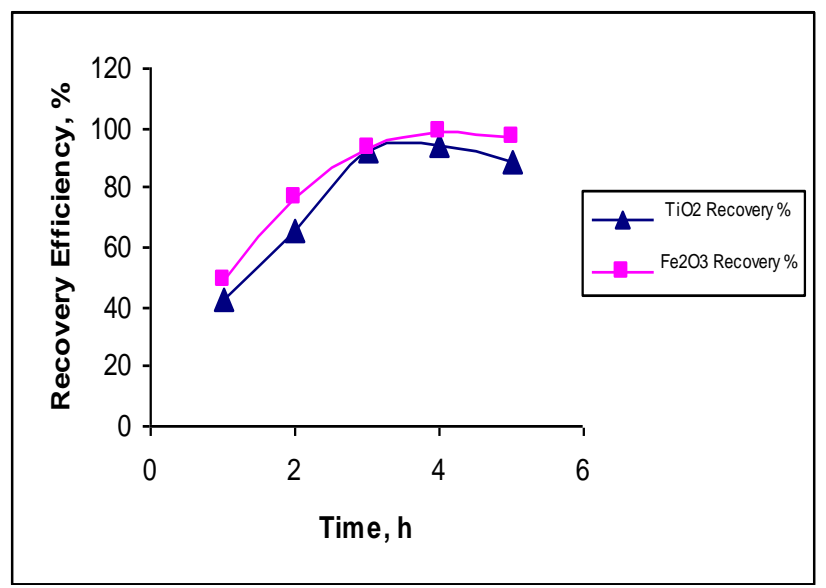

Fig 4: Rate of dissolution of titanium and iron from ilmenite and slag mixing (slag $20 \%, 140{ }^{\circ} \mathrm{C}, 9.2 \mathrm{M} \mathrm{H}_{2} \mathrm{SO}_{4}, \mathrm{~S} / \mathrm{L}$ ratio $1 / 5)$.

\section{Effect of temperature}

In the present work, several dissolution experiments were performed at temperatures ranging from room temperature to $180^{\circ} \mathrm{C}$ under optimum leaching conditions. The results in Fig. 5 show that the extent of titanium and iron dissolution increases significantly with temperature. At room temperature, only $20.83 \%$ titanium and $29.75 \%$ total iron dissolve, respectively. The low titanium dissolution at room temperature is due to the low reactivity of ilmenite and slag. At $140{ }^{\circ} \mathrm{C}$, about 94\% titanium dissolves but increasing the temperature to $180{ }^{\circ} \mathrm{C}$, seriously decreases affects titanium and total iron recovery, this due to the hydrolysis of titanyl sulfate $\mathrm{TiOSO}_{4}$ to give hydrated titanium dioxide $\mathrm{TiO}(\mathrm{OH})_{2}$ and give white precipitate. Therefore, temperature plays an important role in the hydrolysis of dissolved $\mathrm{TiOSO}_{4}$ and $140{ }^{\circ} \mathrm{C}$ would be considered as the optimum temperature for dissolution of about $94 \%$ of titanium and $98.9 \%$ of total iron.

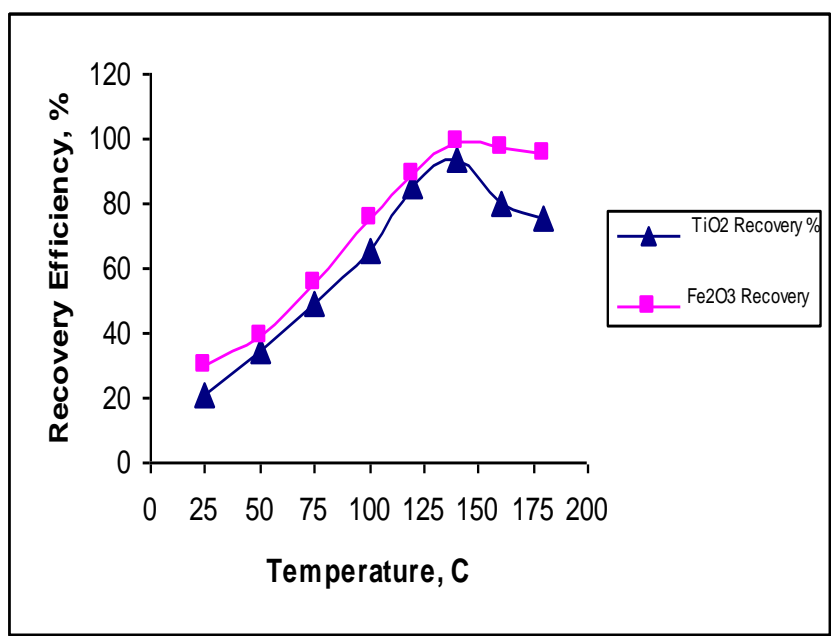

Fig 5: Effect of temperature on titanium and iron dissolution from ilmenite and slag mixing (slag $20 \%, 140{ }^{\circ} \mathrm{C}, 9.2 \mathrm{M}$ $\mathrm{H}_{2} \mathrm{SO}_{4}, 4 \mathrm{~h}, \mathrm{~S} / \mathrm{L}$ ratio $1 / 5$ ).

\section{Conclusions}

To resolve the problem that the increasing of the pulp density in the leaching of titanium using concentrated sulfuric acid we can use titania slag as a reductive agent with ratio $20 \%$ which give high recovery for titanium dioxide $94 \%$ under optimum conditions $9.2 \mathrm{M}$ sulfuric acid at a solid/liquid ratio of $1 / 5$ at $140^{\circ} \mathrm{C}$ for $4 \mathrm{~h}$ and using an ore ground to -325 mesh size. By using these optimum conditions for leaching ilmenite only gives low titanium recovery $76.0 \%$ and iron $40.5 \%$. On the other hand for leaching titania slag only with the same optimum conditions gives titanium recovery $69.7 \%$ and iron $59.7 \%$.

\section{References}

1) Yang, S., Liu, Y., Guo, Y., Zhao, J., Xu, H. and Wang, Z. (2002). Preparation of rutile titania nanocrystals by liquid method at room temperature. J. Mater. Chem. Phys. 77: 501-506. 
2) Watson, S., Beydoun, D., Scott, J., and Amal, R. (2004). Preparation of nanosized crystalline $\mathrm{TiO}_{2}$ particles at low temperature for photocatalysis. J. Nanopart. Res. 6: 193-207.

3) Fujishima, A., Rao, T. N. and Tryk, D. A. (2000). Titanium dioxide photocatalysis. J. Photochem. Photobiol. C: Photochem. Rev. 1, 1-21.

4) Becher, R. G., Canning, R. G., Goodheart, B. A. and Uusna, S. (1965). A new process for upgrading ilmenite minerals sands. Proc. Aust. Inst. Min. Metall. 214: 1261-1283.

5) Benelite Corp. of America, (1974). U.S. Patent No. $3,825,419$.

6) Schoukens, A. E. S., Morris, D. J. and Stephen, M. C. (2004). Production of high titania slag from ilmenite. US Patent. No. 6,733,561 B2.

7) Mahmoud, M. H. H., Afifi, A. A. and Ibrahim, I. A. 2004. Reductive leaching of ilmenite ore in hydrochloric acid for preparation of synthetic rutile. Hydrometallurgy 73: 99-109.

8) Lasheen, T. A. I. (2005). Chemical beneficiation of Rosetta ilmenite by direct reduction leaching. Hydrometallurgy 76: 123-129.

9) Lasheen, T. A. I. (2006). Benefication of titaniferous beach sand ilmenite. Chem. 04 Biannual Conference on Chemistry. Cairo University, pp. 349-358.

10) Van Dyk, J. P., Vegter, N. M., Visser, C. P., de Lange, T., Winter, J. D., Walpole, E. A. and Nell, J. (2004). Beneficiation of titania slag by oxidation and reduction treatment. US Patent. No. 6,803,024 B1.
11) Jarish, B. (1977). Upgrading Sorelslag for production of synthetic rutile. US Patent No. $4,038,363$.

12) Sahu, K. K., Alex, T. C, Mishra, D. and Agrawal, A. (2006). An overview on the production of pigment grade titania from titania-rich slag. Waste Management Research 24: 74-79.

13) Gueguin, M. (1978). Chlorination of titanium slags. US Patent. No. 4,078,039.

14) Gueguin, M. (1990). Method of preparing a synthetic futile from a titaniferous slag containing magnesium values. US Patent. No. 4,933,153.

15) Gueguin, M. (1991). Method of preparing a synthetic rutile from a titaniferous slag containing magnesium values. US Patent. No. 5,063,032.

16) Gueguin, M. (1995). Method of preparing a synthetic futile from a titaniferous slag containing alkaline earth metals. US Patent. No. 5,389,355.

17) Elger, G. W. and Kirby, D. E. (1976). Synthesis of futile from titaniferous slag. US Patent. No. 3,996,332.

18) Elger, G. W. and Holmes, R. A. (1982). Purifying titanium-bearing slag by promoted sulfating. US Patent. No. 4,362,557.

19) Borowiec, K. (1991). Sulphidization of solid titania slag. Scandinavian Journal of Metallurgy 20: 198204.

20) Borowiec, K., Grau, A. E., Gueguin, M., Turgeon, J. E. (1998). Method to upgrade titania slag and resulting product. US Patent. No. 5,830,420. 